\title{
LEACH and Extended LEACH Protocols in Wireless Sensor Network-A Survey
}

\author{
Amandeep Kaur \\ SBS State Technical Campus \\ Moga Road, Ferozepur-152004
}

\author{
Amit Grover \\ SBS State Technical Campus \\ Moga Road, Ferozepur-152004
}

\begin{abstract}
Wireless Sensor Network is collection of wireless sensor nodes in which routing protocol is most challenging issue. Sensors have limited battery power. Battery extends the lifetime of sensor nodes. Energy utilization is one of the most important considerations. There are various routing techniques which increase lifetime of battery. One of the most energy efficient clustering routing protocols is LEACH. In this survey paper we represent LEACH \& Extended version of LEACH routing protocol. Some issues are faced by LEACH. In this paper we represent how Extended LEACH version tackled these issues. We compare Extended LEACH Protocols with original LEACH.
\end{abstract}

\section{Keywords}

Cluster Head (CH), Time division multiple access (TDMA), Cluster member (CM), Base Station (BS), Wireless Sensor Network (WSN).

\section{INTRODUCTION}

Wireless Sensor Network is renowned as most important technology in twenty-first century [2]. A wireless sensor network builds from large number of sensor nodes that bring themselves together to form a wireless network. Sensor nodes are in small size and battery-powered devices. Routing in WSNs is very challenging from other wireless networks because sensor nodes have low battery power and replace the batteries is costly [9]. WSN are used for many applications such as flood detection, home automation, environmental monitoring, forest fire detection etc. [1]. Various routing protocols are available to increase the lifetime of network. Hierarchical routing protocols are more energy efficient routing protocols. In this network is divided into various clusters [11]. In every cluster, single node is considered as a cluster head $(\mathrm{CH})$ and non cluster head nodes are treated as cluster members (CM).In every cluster, cluster head gathers the data from the cluster members and aggregate this data and broadcast this data to Base station through single-hop or multi-hop. CHs utilize more energy than the CM [13]. So clustering protocols distributes the load of the $\mathrm{CHs}$ amongst the sensor nodes and their role is revolved among all nodes for energy-consumption equalization. LEACH is first energy efficient clustering routing protocol. But LEACH has some drawbacks. Many protocols are derived from LEACH with some modification such as Two-Level LEACH, multi-hop LEACH, E-LEACH, Vice-Cluster Head LEACH, Mobile LEACH, Advanced LEACH (LEACH-A), Balanced LEACH, LEACH-S. This survey paper discus these Extended-LEACH and compare with original LEACH. Bajaber, Fuad G. (Awan, Irfan U.) [13] Proposed an energy efficient clustering protocol

(EECPL) to improve the duration of WSN. EECPL decrease power utilization and increase duration of WSN by allocating energy load between all sensor nodes. Zahoor A. Khan, Srinivas Sampall [15] proposed AZR-LEACH to enhance duration of WSN. In AZR-LEACH static clustering is used for the efficient selection of cluster heads. This routing protocol works efficiently in large as well as small areas.

\section{LEACH PROTOCOL}

LEACH is "Low Energy Adaptive Clustering Hierarchy" routing protocol and it is $1^{\text {st }}$ energy efficient cluster based routing protocol used to enhance the lifetime of wireless sensor network. LEACH include distribution cluster algorithm. In each cluster one node considered as cluster head $(\mathrm{CH})$ and remaining nodes as cluster members (CMs) and in LEACH rotate this role at every round. Because cluster head consume more energy than cluster members and if one node is selected permanently as $\mathrm{CH}$ then it will die soon. In each round made of two phases are:-

1. Set-up phase

2. Steady state phase

In setup phase cluster heads are created using formula:-

$$
T(n)= \begin{cases}\frac{P}{1-P\left(r \bmod \frac{1}{P}\right)} & \text { if } n \in G \\ 0 & \text { othewise }\end{cases}
$$

Where $P$ is suggested percentage, $G$ is set of nodes which are not elected as cluster head in previous $1 / \mathrm{P}$ rounds and $\mathrm{r}$ is recent round [9]. Nodes select themselves as cluster head $(\mathrm{CH})$ on behalf of suggested percentage $(\mathrm{P})$ and its earlier record of $\mathrm{CH}$ [11]. The node that is elected as cluster head in current round, it will become cluster head again after $1 / \mathrm{P}$ rounds $[1,4]$. This is for uniform energy dissipation throughout the network. Selected CHs send an advertisement packet to other nodes which are not elected as cluster head to join their cluster. These nodes send joint request to those cluster heads $(\mathrm{CHs})$ from which they receive advertisement packet with strongest signal power.

After formation of cluster, $\mathrm{CH}$ create TDMA schedule for its CM in cluster, pick CSMA code and send TDMA schedule table to its cluster members. In Steady State Phase cluster members transmits data to its cluster heads $(\mathrm{CHs})$ according to allocated TDMA time slots. Cluster heads gathers data from its cluster members and aggregates this data to decrease amount of data that broadcast to base station.

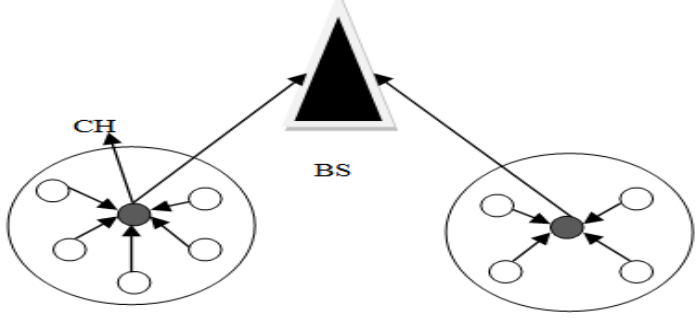

Fig 1: LEACH Protocol 


\section{EXTENDED LEACH PROTOCOL'S}

\subsection{TL-LEACH (Two Levels LEACH)}

In original $\mathrm{LEACH}$, within its cluster $\mathrm{CHs}$ collect data from its cluster members (CMs), aggregates it and broadcasts data to Base station (BS). But most of the time $\mathrm{CHs}$ located away from Base station and use more power to send data to Base station (BS). So new extended version of LEACH introduced which is TL-LEACH. In TL-LEACH within its cluster CHs gather data from its cluster members and transmit data to another cluster head $(\mathrm{CH})$ which lies between cluster head and Base station. TL-LEACH reduces more energy consumption than original LEACH and also reduces number of nodes to transmit data to Base station.

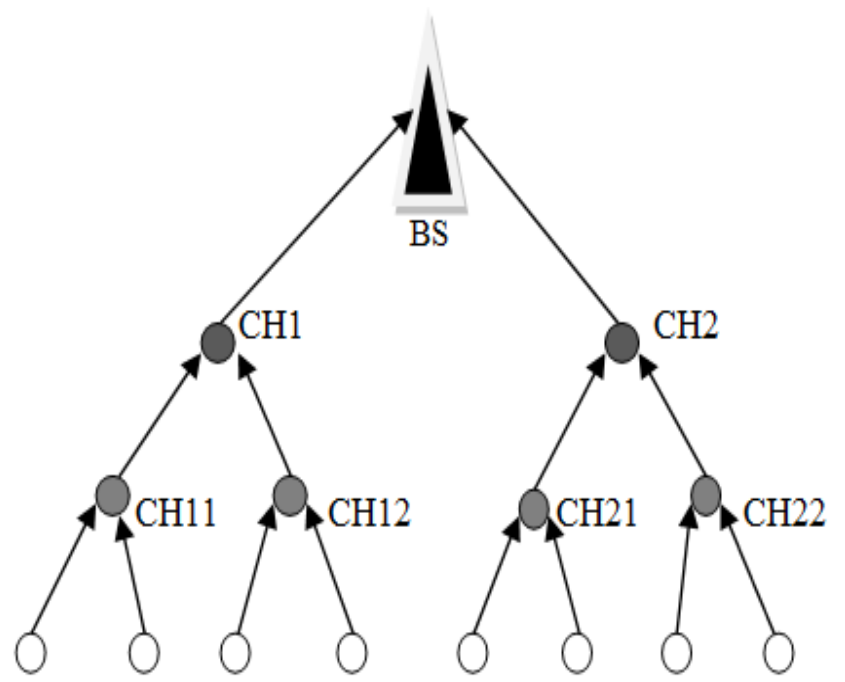

Fig 2: TL-LEACH

\subsection{LEACH-C (Centralised LEACH)}

LEACH-C is different from original LEACH in cluster formation but its operation similar to original LEACH Protocol. LEACH-C perform centralised cluster algorithm for selection of cluster heads (CHs). In LEACH-C setup phase is similar to original LEACH but Steady state phase is different. Base station (BS) collects location data and energy level related information from each node. Now base station has global information of network. Base station calculates average node energy. Nodes have energy more than average energy is elected as cluster heads. LEACH-C use GPS or other location tracking methods. Base station sends its decision back to nodes that which nodes are elected as cluster heads. Base station broadcasts $\mathrm{CHs}$ ID(identifier) to nodes in network and nodes have same ID as elected CHs ID are nominated as $\mathrm{CH}$ and collect data from its cluster members using TDMA schedule [5] [6]. Centralised-LEACH uses a deterministic threshold algorithm in which amount of energy in the node and/or whether or not the node was a cluster head in recent time. The number of $\mathrm{CH}$ nodes and their placement cannot be assured. The central control algorithm is used in CentralisedLEACH to form the clusters which produce improved clusters by distributing the cluster head nodes through the network. [6][7].

\subsection{Multi-Hop LEACH}

In LEACH distance between Base station and $\mathrm{CH}$ has no effect. Data transmitted from $\mathrm{CHs}$ to base station in single hop communication. As diameter of network increased, distance between Cluster head $(\mathrm{CH})$ and base station also increased [4]. Power consumption of battery will increase as distance increased. Therefore in order to reduce energy consumption modified protocol Multihop LEACH introduced. In Multihop LEACH data broadcasts from cluster head $(\mathrm{CH})$ to base station occur in multi hop communication [8]. In Multihop LEACH data transmitted from one $\mathrm{CH}$ to other $\mathrm{CH}$, then to other $\mathrm{CH}, \mathrm{CH}$ which is near to Base station transmits whole data to Base station (BS). Multi-hop LEACH is a distributed routing protocol based upon clustering [14]. Cluster Heads $(\mathrm{CHs})$ perform data aggregation to the data receive in order to reduce the total data broadcasted in the network [3], [4], [6].

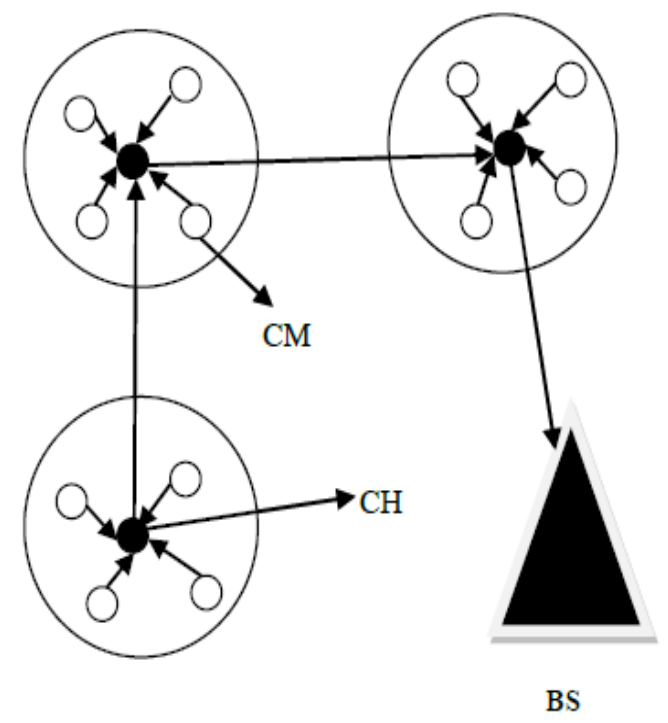

Fig 3: MULTIHOP LEACH

\subsection{E-LEACH (Enhanced-LEACH)}

Enhanced LEACH is introduced to handle overload power consumption problem based on LEACH protocol. E-LEACH involves cluster head selection algorithms which have global information about the other sensor nodes [6]. The main factor that affects the overall performance of hierarchical clustering routing protocols is the total number of cluster heads. As there are less number of cluster heads then each $\mathrm{CH}$ has to cover large area, it will results the trouble that cluster members (CMs) which are at far distance from their $\mathrm{CHs}$ consume more energy [3]. Large number of $\mathrm{CHs}$ will consume more energy and decrease lifetime of network. So it needs to select only optimal cluster head have large residual energy in order to reduce energy utilization. Residual energy of sensor nodes considered as most important factor, it makes a decision that sensor node turn into cluster head or not in next round. Communication between $\mathrm{CHs}$ and base station needs more energy than communication between $\mathrm{CHs}$ and cluster members. E-LEACH choose that nodes as $\mathrm{CH}$ that have large residual energy at root node.

\subsection{LEACH-A (Advanced LEACH)}

In original $\mathrm{LEACH}$ protocol $\mathrm{CH}$ is responsible for transmits data directly to base station and cluster head $(\mathrm{CH})$ consume extra energy than cluster member (CM) nodes in network. ALEACH is extension of LEACH. Hence in Advanced LEACH protocol energy conserving and reliable data transfer both are improved [6]. In Advanced-LEACH, the data is processed with mobile agent technique. 


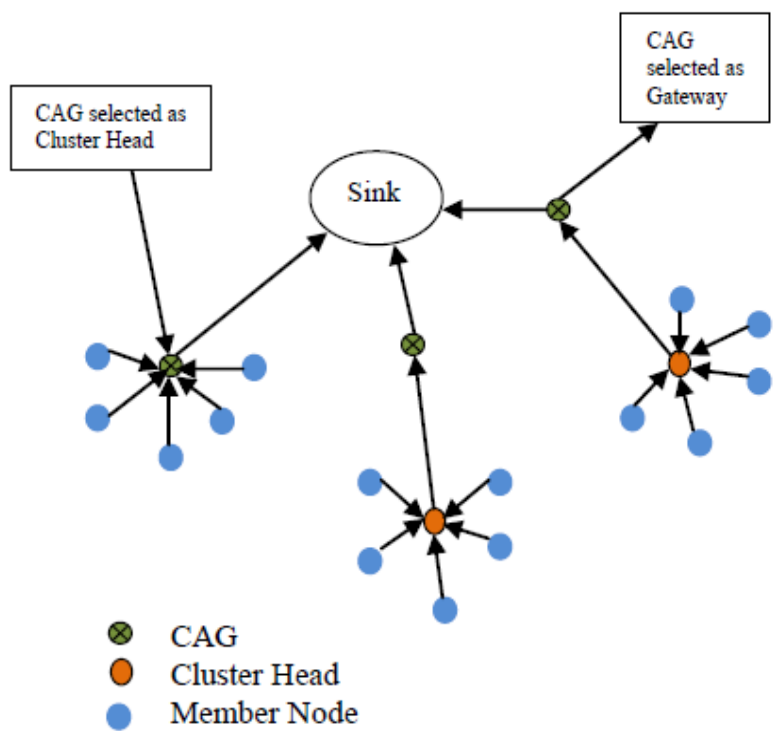

Fig 4: Advanced-LEACH

Advanced-LEACH is proposed for the purpose of reliable data transfer, energy saving, decreasing the chance of failure of sensor nodes and for increasing the time interval before the first node dies. A-LEACH uses synchronized clock through which sensors get starting time of each round [6],[9]. CAG nodes are set with time more energy than other nodes. CAG used as gateway or cluster head and rest nodes are used as normal nodes.

A-LEACH protocol has following advantages:

1. The data is collaborates to reducing the quantity of data that is broadcasted to the Base Station [15].

2. The CAG nodes continue to send data to base station when all normal nodes die.

3. The Gateways extend the lifetime of network by reducing energy consumption.

4. Gateways reduce probability of node's failure and increase time interval before first node dies.

5. Advanced-LEACH use TDMA/CDMA techniques that create clustering on several levels. It saves more energy.

\subsection{LEACH-B (Balanced LEACH)}

Balanced-LEACH is an improvement of original LEACH Protocol. In LEACH-B decentralized algorithms used for formation of clusters. In Leach-B sensor nodes have knowledge about its own position and destination receiver position and have no information about location of other sensor nodes. In Balanced-LEACH data transmits using multiple access techniques. Each sensor nodes selects its cluster head, by analysing the energy lost in the pathway between final recipient and itself. Efficiency of BalancedLEACH protocol is better as compared to original LEACH protocol.

\subsection{Vice-Cluster Head LEACH (V- \\ LEACH)}

The main disadvantage of fundamental LEACH that there is a cluster head in each cluster and it dies when it does not have enough energy to send cluster member's data to the base station [13]. All the data with that cluster head is lost when it dies. In LEACH protocol cluster head randomly chooses that is another disadvantage. To overcome these disadvantages $\mathrm{V}$ LEACH has introduced the concept Vice Cluster Head.

1. A vice cluster node will become a cluster head of the cluster when the existing cluster head dies [13].

2. It is CH's responsibility to collect from its cluster members and send data that to base station.

3. When $\mathrm{CH}$ dies due to low power then vice cluster head sends data to base station.

V-LEACH has no solution when vice cluster head dies. In VLEACH the $\mathrm{CH}$ and Vice- $\mathrm{CH}$ are selected on the behalf of Energy, Residual Energy and Distance. The V-LEACH will increase lifetime of network.

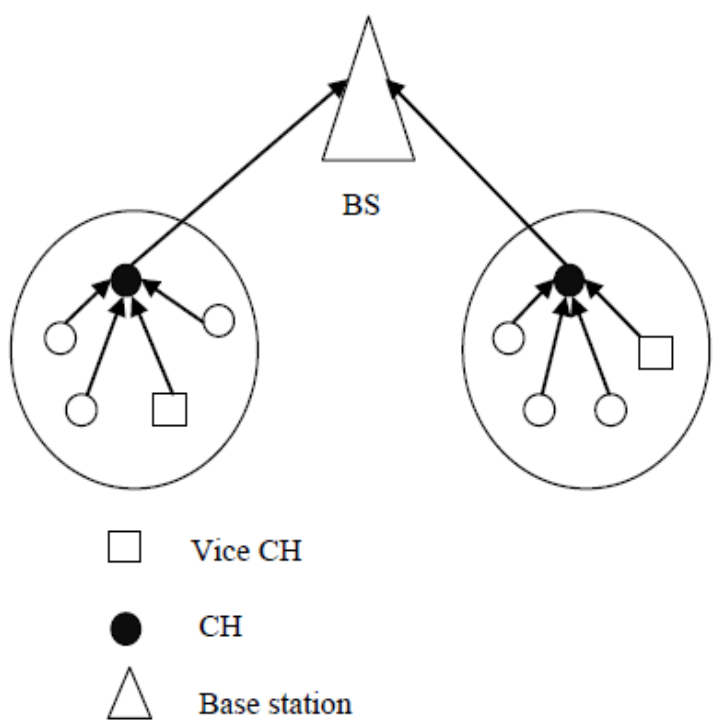

Fig 5: V-LEACH

\subsection{LEACH-M (Mobile-LEACH)}

In the routing based LEACH protocol Mobility support is an essential concern. To overcome this issue Mobile-LEACH is proposed. In LEACH-M protocol, during the set-up and steady phase, cluster head nodes and cluster member nodes can move [12]. In Mobile-LEACH base station is fixed, initially the nodes are assumed to be homogeneous and information about their location gets through GPS. Base station is assumed to be fixed [4]. In LEACH-M distributed setup phase of original LEACH is modified to select suitable cluster head. On the basis of minimum mobility and lowest attenuation energy the optimal $\mathrm{CHs}$ are selected, that transmit their position to all nodes in cluster which are in its communication range. Either member nodes move away from the cluster head or cluster-head moves away from its cluster member nodes another cluster head is elected in the steady state phase of fundamental routing LEACH protocol which results into ineffective clustering formation. Mobile-LEACH offers a handover mechanism for nodes to switch on to new cluster-head to deal with this problem [6] [11].

\subsection{LEACH-L (Energy Balanced LEACH)}

LEACH-L is energy balanced advanced multi-hop cluster based routing protocol. It is only depends upon distance. In LEACH-L the optimal hop counts are assumed. When cluster heads are sited near to BS (Base Station), then they directly communicate with BS. Cluster heads communicate via multihop mode when they are sited far away from the BS, and 
shortest communication distance is limited. In LEACH-L sensors nodes communicate with BS at different frequencies. The clusters are reorganized in each round and there are two phase: set-up phase and steady phase in each round. The new $\mathrm{CHs}$ are selected in each round. Load is circulated and balanced between all the nodes in the senor network. LEACH$\mathrm{L}$ covers large area than Mobile-LEACH because LEACH-L allocates equal power among all the senor nodes in the preperiod [6], [12].

\subsection{LEACH-S (Solaraware Centralized LEACH)}

In LEACH-S solar power extends the lifetime of sensor nodes in wireless sensor network. In LEACH- S, the base station applies the improved central control algorithm to select $\mathrm{CH}$ (Cluster Head). Base station generally selects solar powered nodes that have maximum remaining power. In SolarLEACH, nodes send out its solar status to the BS along with the power left in them and nodes with higher power are chosen as the $\mathrm{CH}$ (cluster head). As soon as numbers of solar nodes are increases the performance of wireless sensor network also increases. The duration of sun extend the lifetime of the sensor nodes in WSN. But if the sun duration is smaller cluster head handover is obtain in LEACH-S [11] [12].

\subsection{LEACH-S (Solaraware Distributed LEACH)}

In this LEACH-S, cluster head is selected by to solar driven nodes that have maximum probability as compared to batterydriven nodes [6].

Table 1. Comparison

\begin{tabular}{|c|c|c|}
\hline $\begin{array}{l}\text { EXTENDED LEACH } \\
\text { PROTOCOLS }\end{array}$ & AbBreviations & $\begin{array}{l}\text { COMPARISON WITH } \\
\text { ORIGINAL LEACH }\end{array}$ \\
\hline TL-LEACH & $\begin{array}{l}\text { Two Levels } \\
\text { LEACH }\end{array}$ & $\begin{array}{l}\text { A CH that lies between } \\
\text { the } \mathrm{CH} \text { and } \mathrm{BS} \text { sends } \\
\text { the Data to BS. }\end{array}$ \\
\hline LEACH-C & $\begin{array}{l}\text { Centralised } \\
\text { LEACH }\end{array}$ & $\begin{array}{l}\text { By using Centralized } \\
\text { Cluster Algorithm BS } \\
\text { is Responsible for } \\
\text { making Clusters for } \\
\text { each round. }\end{array}$ \\
\hline $\begin{array}{l}\text { MULTIHOP } \\
\text { LEACH }\end{array}$ & $\begin{array}{l}\text { MULTIHOP } \\
\text { LEACH }\end{array}$ & $\begin{array}{l}\text { In Multihop LEACH } \\
\text { data communication } \\
\text { from cluster heads } \\
\text { (CHs) to base station } \\
\text { take place in multi hop } \\
\text { communication. }\end{array}$ \\
\hline E-LEACH & $\begin{array}{l}\text { Enhanced- } \\
\text { LEACH }\end{array}$ & $\begin{array}{l}\text { Selection of } \mathrm{CH} \text { is on } \\
\text { the basis of Residual } \\
\text { Energy. }\end{array}$ \\
\hline LEACH-A & $\begin{array}{l}\text { Advanced- } \\
\text { LEACH }\end{array}$ & $\begin{array}{l}\text { A-LEACH is a mixed } \\
\text { energy protocol } \\
\text { planned for the } \\
\text { purpose of reliable data } \\
\text { transfer, energy saving. }\end{array}$ \\
\hline
\end{tabular}

\begin{tabular}{|l|l|l|}
\hline LEACH-B & Balanced-LEACH & $\begin{array}{l}\text { LEACH-B Choose its } \\
\text { CH by calculating the } \\
\text { Energy required for the } \\
\text { Path Between itself } \\
\text { and Destination. }\end{array}$ \\
\hline V-LEACH & $\begin{array}{l}\text { Vice-Cluster Head } \\
\text { LEACH }\end{array}$ & $\begin{array}{l}\text { When CH dies the vice } \\
\text { CH send all data to BS. }\end{array}$ \\
\hline LEACH-M & MOBILE-LEACH & $\begin{array}{l}\text { Mobile LEACH is } \\
\text { Suited for Mobility } \\
\text { Centric Environment. }\end{array}$ \\
\hline LEACH-L & $\begin{array}{l}\text { Energy Balanced } \\
\text { LEACH }\end{array}$ & $\begin{array}{l}\text { Cluster head selected } \\
\text { on basis of distance. }\end{array}$ \\
\hline LEACH-S & $\begin{array}{l}\text { SOLARAWARE } \\
\text { CENTRALIZED } \\
\text { LEACH }\end{array}$ & $\begin{array}{l}\text { CH is chosen on basis } \\
\text { of Residual Energy } \\
\text { Level. }\end{array}$ \\
\hline
\end{tabular}

\section{CONCLUSION}

In this paper, the most important issue is energy efficiency in designing cluster based routing protocols for WSN (Wireless Sensor Network), because sensor nodes have limited energy. Sensor nodes mostly consume energy during data broadcastand reception. So, routing protocols used in Wireless Sensor Network should be energy efficient to increase not only the individual node lifetime, but also extend the lifetime of the whole of the wireless sensor networks. There are various routing protocols but we have selected LEACH protocol because it gives better performance in both the energy efficiency and the network lifetime. LEACH can overcome the problem of Wireless Sensor Network. LEACH has many advantages but along with advantages some disadvantages are also present. To overcome these disadvantages many descendants of LEACH protocol are introduced like TL-LEACH, E-LEACH, LEACH-M, LEACH-C, Multihop LEACH and V-LEACH, L-LEACH, Fixed-LEACH A-LEACH, S-LEACH etc are explained in this paper. These extended LEACH protocols or LEACH descendant's provides better result than Original LEACH. Each Extended LEACH protocols have some advantages as compared to the original LEACH protocol and fundamentals one. But still needs to find more efficient cluster based routing protocol to improve the performance of Wireless Sensor Network.

\section{REFERENCES}

[1] S. ELkhediri, N. Nasri, A. Kachouri, Diverses"Synchronization Issues in Wireless Sensors Networks", IEEE the 23 International Conference of Microelectronics. TUNISIA: ICM, 2011.

[2] "21 ideas for the $21^{\text {st }}$ century", Business week, Aug.30 1999, pp.78-167.

[3] Sapna Choudhary1, Sandeep Sharma2, International Journal of Advanced Research in Computer Science and Software Engineering Vol. 4, Issue 1, January 2014.

[4] Ravneet Kaur1, Deepika Sharma2, Navdeep Kaur3,"Comparative Analysis Of Leach and Its Descendant Protocols In Wireless Sensor Network" International Journal of P2P Network Trends and Technology-Vol. 3, Issue 1-2013 
[5] Salim EL KHEDIRIa,b,c, Nejah NASRIa, Anne WEIc, Abdennaceur KACHOURId," A New Approach for Clustering in Wireless Sensors Networks Based on LEACH" science direct International Workshop on Wireless Networks and Energy Saving Techniques (WNTEST)

[6] J.Gnanambigai\#1,Dr.N.Rengarajan\#2,K.Anbukkarasi\#3 Leach and Its Descendant Protocols: A Survey" International Journal of Communication and Computer Technologies Volume 01 - No.3, Issue: 02 September 2012

[7] X.H.Wu, S. Wang,"Performancecomparison of LEACH and LEACH-C protocols by NS-2," Proceedings of $9^{\text {th }}$ International Symposium on Distributed Computing and Applications to Business, Engineering and Science. Hong Kong, China, pp 254-258,2010

[8] RajashreeV.Biradar,Dr.S.R.Sawant,Dr.R.R.Mudholkar, Dr.V.C.Patil "Multihop Routing In Self-Organizing Wireless Sensor Networks" IJCSI International Journal of Computer Science Issues,Vol.8,Issue 1,Januaray 2011

[9] EZZATIABDELLAH, SAIDBENALLA, Abderrahim BENIHSSANE,MoulayLahcenHASNAOUI,"Advanced Low Energy Adaptive Clustering Hierarchy" EzzatiAbdellah etal/ (IJCSE) International Journal on Computer Science and Engineering, Vol.02.No.07, 2010, 2491-2497.
[10] Lan Tien Nguyen $\dagger 1$, Xavier Defago $\dagger 2$, Razvan Beuran $* \uparrow 3$, Yoichi Shinoda $\uparrow * 4$ IEEE ISWCS 2008.

[11] M. Aslam1, N. Javaid2, A. Rahim3, U. Nazir4, "Survey of Extended LEACH-Based Clustering Routing Protocols for Wireless Sensor Networks" [cs.NI] 11 July 2012.

[12] P. Manimala1, R. Senthamil selvi2, International Journal of Emerging Technology and Advanced Engineering Website: www.ijetae.com (ISSN 22502459, ISO 9001:2008 Certified Journal, Vol. 3, Issue 12, December 2013).

[13] Bajaber, Fuad G. (Awan, Irfan U.). "Performance Analysis of Cluster Based Communication Protocols for Energy Efficient Wireless Sensor Networks. Design, Analysis and Performance Evaluation of Communication Protocols under Various Topologies to Enhance the Lifetime of Wireless Sensor Networks.", University of Bradford, 2011.

[14] Sabri, Alia and Al-Shqeerat, Khalil "Hierarchical Cluster-Based Routing Protocols for Wireless Sensor Networks -- A Survey", International Journal of Computer Science.

[15] Khan, Zahoor A. and Sampalli, Srinivas. "AZRLEACH: An Energy Efficient Routing Protocol for Wireless Sensor Networks", International Journal of Communications, Network \& System Sciences, 2012. 